Portland State University

PDXScholar

\title{
Modeling and Analyzing the Impact of Advanced Technologies on Livability and Multimodal Transportation Performance Measures in Arterial Corridors: Phase 2
}

\author{
Miguel A. Figliozzi \\ Portland State University, figliozzi@pdx.edu \\ Chawalit Tipagornwong \\ Portland State University
}

Follow this and additional works at: https://pdxscholar.library.pdx.edu/trec_reports

Part of the Transportation Commons, Urban Studies Commons, and the Urban Studies and Planning Commons

Let us know how access to this document benefits you.

\section{Recommended Citation}

Figliozzi, Miguel A. Modeling and Analyzing the Impact of Advanced Technologies on Livability and Multimodal Transportation Performance Measures in Arterial Corridors, Phase 2. NITCRR-760. Portland, OR: Transportation Research and Education Center (TREC), 2017. https://doi.org/10.15760/trec.165

This Report is brought to you for free and open access. It has been accepted for inclusion in TREC Final Reports by an authorized administrator of PDXScholar. Please contact us if we can make this document more accessible: pdxscholar@pdx.edu. 

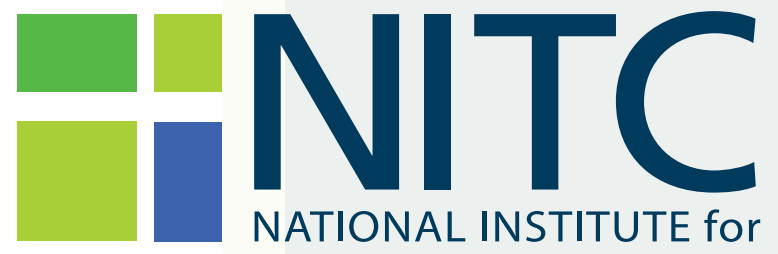

TRANSPORTATION and COMMUNITIES

\section{FINAL REPORT}

Modeling and Analyzing the Impact of Advanced Technologies on Livability and Multimodal Transportation Performance Measures in Arterial Corridors: Phase 2

NITCN-RR-760 — March 2017

NITC is a U.S. Department of Transportation national university transportation center.

HI! TREC 



\title{
MODELING AND ANALYZING THE IMPACT OF ADVANCED TECHNOLOGIES ON LIVABILITY IN ARTERIAL CORRIDORS $2^{\text {ND }}$ PHASE: FOCUS ON PEDESTRIAN SAFETY
}

\author{
Final Report \\ NITC-RR-760 \\ by \\ Miguel A. Figliozzi \\ Chawalit Tipagornwong
}

Portland State University

for

National Institute for Transportation and Communities (NITC)

P.O. Box 751

Portland, OR 97207
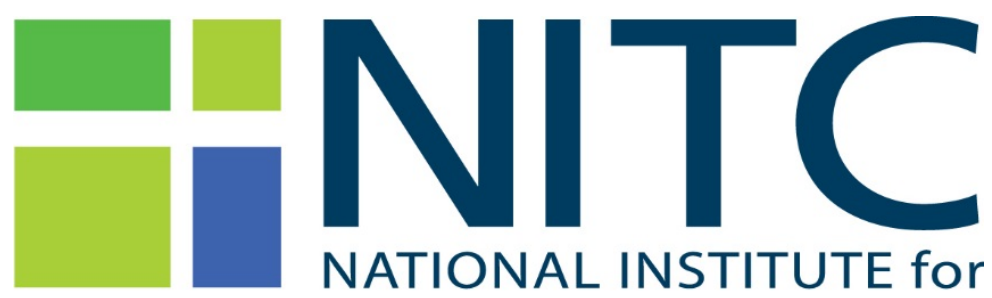

TRANSPORTATION and COMMUNITIES

March 2017 



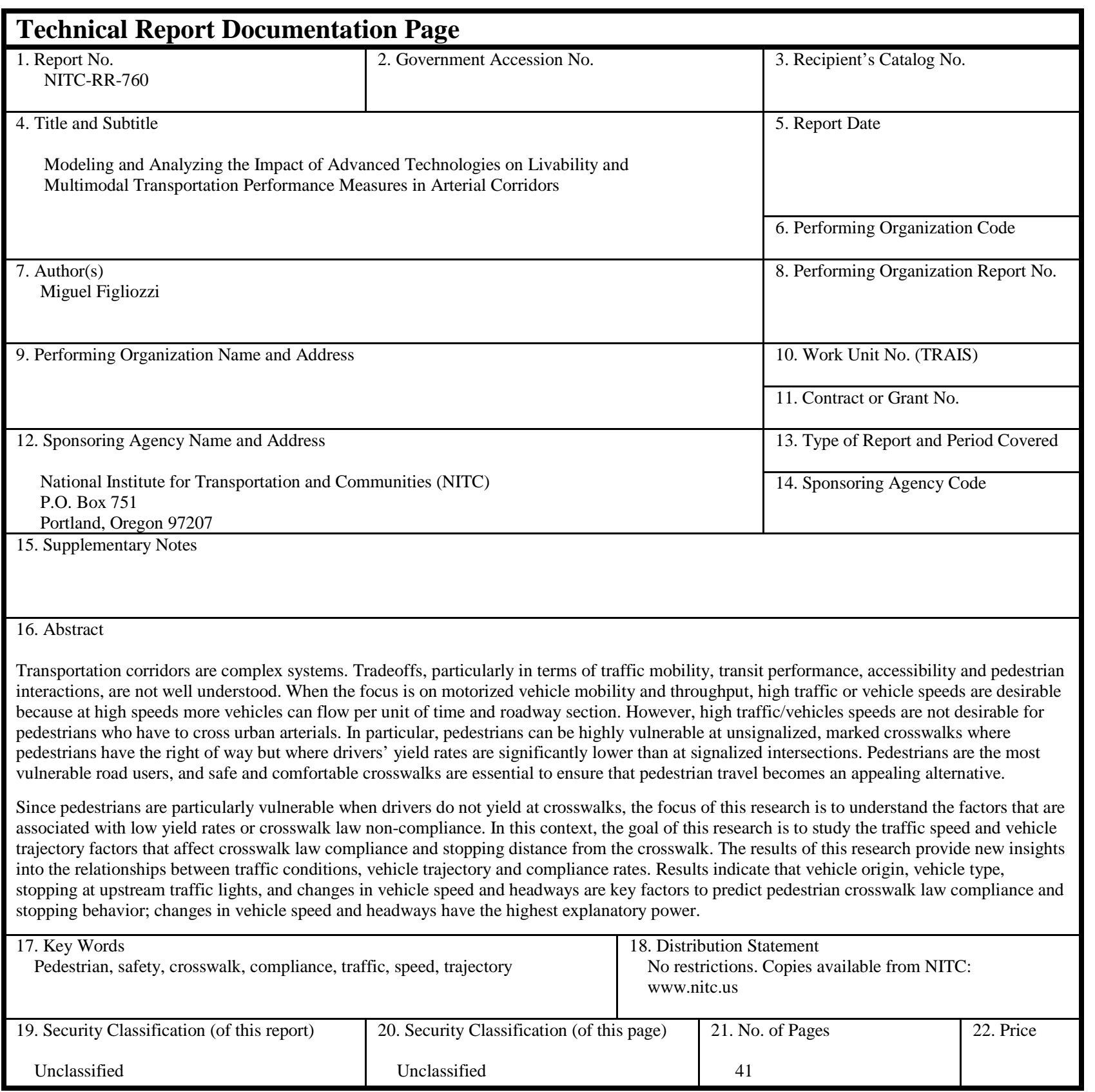





\section{ACKNOWLEDGEMENTS}

We are grateful to the National Institute for Transportation and Communities (NITC) for funding this project.

\section{DISCLAIMER}

The contents of this report reflect the views of the authors, who are solely responsible for the facts and the accuracy of the material and information presented herein. This document is disseminated under the sponsorship of the U.S. Department of Transportation University Transportation Centers Program in the interest of information exchange. The U.S. Government assumes no liability for the contents or use thereof. The contents do not necessarily reflect the official views of the U.S. Government. This report does not constitute a standard, specification, or regulation.

\section{RECOMMENDED CITATION}

Figliozzi, Miguel A. Modeling and Analyzing the Impact of Advanced Technologies on Livability and Multimodal Transportation Performance Measures in Arterial Corridors, Phase 2. NITCRR-760. Portland, OR: Transportation Research and Education Center (TREC), 2017. 



\section{TABLE OF CONTENTS}

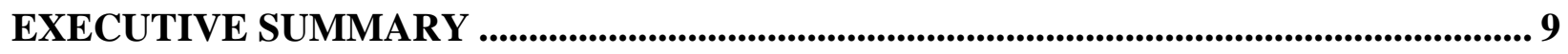

1.0 MOTIVATION ......................................................................................................... 11

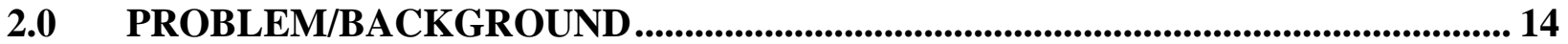

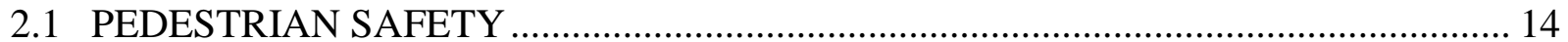

2.2 PEDESTRIAN CROSSWALK LAWS ................................................................ 14

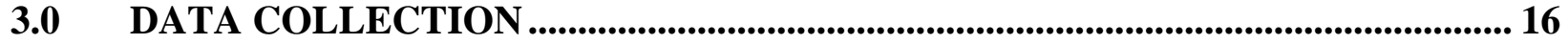

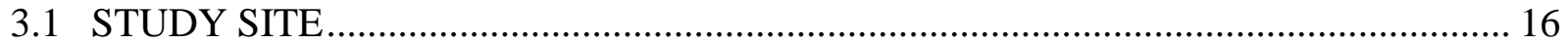

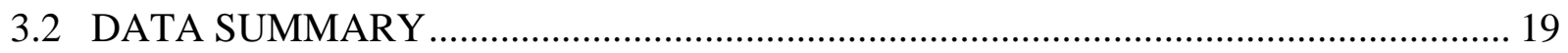

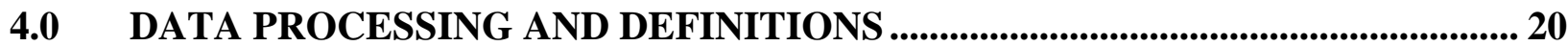

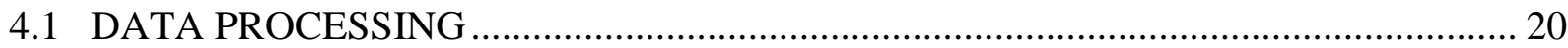

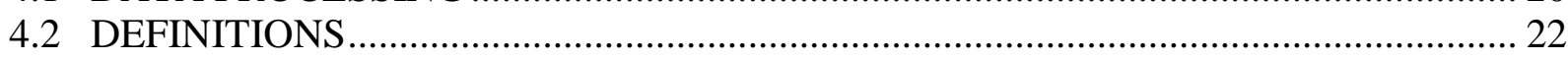

5.0 BINARY LOGISTIC MODELING RESULTS .................................................... 25

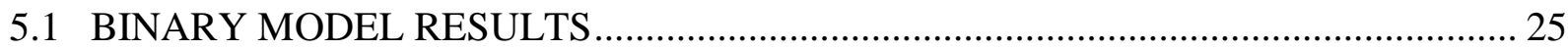

5.2 NEAR CROSSWALK VARIABLES................................................................ 27

6.0 ORDERED LOGISTIC MODELING RESULTS ..................................................... 29

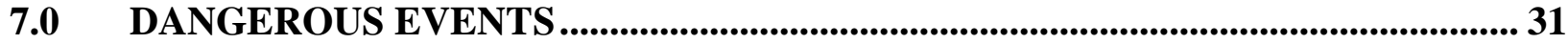

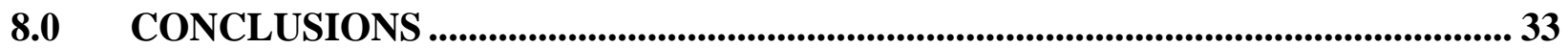

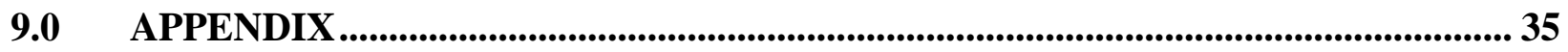

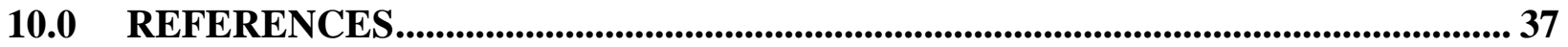




\section{LIST OF TABLES}

Table 1. Data Dictionary for Binary Logistic and Ordered Logistic Regression Models ............ 23

Table 2. Final Compliance Model .................................................................................. 26

Table 3. Compliance Model - Ceteris Paribus Log-likelihood Change ...................................... 26

Table 4. Final Compliance Model with only College Variables .............................................. 28

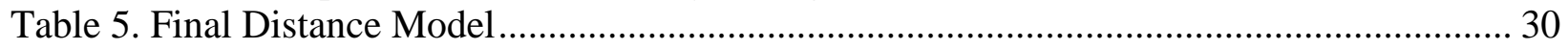

Table 6. Descriptive Statistics - Significant Continuous/Integer Variables............................... 35

Table 7. Descriptive Statistics - Significant (bold) and Related Binary Variables ..................... 35

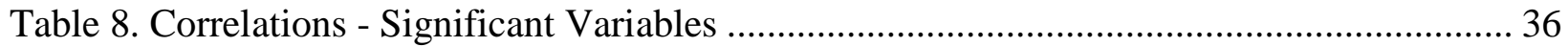




\section{LIST OF FIGURES}

Figure 1. Illustration of the "safety buffer” concept (ODOT, 2015) ........................................ 12

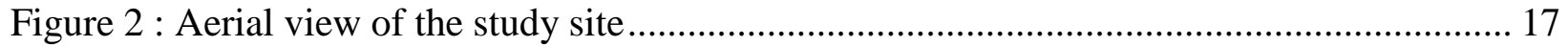

Figure 3 : Schematic view of the study site, distances (in feet) and three drivers' perspectives.. 18 



\section{EXECUTIVE SUMMARY}

Tradeoffs, particularly in terms of traffic mobility, transit performance, accessibility and pedestrian interactions, are not well understood. When the focus is on motorized vehicle throughput, high vehicle speeds are desirable because at high speeds more vehicles can flow per unit of time and roadway section. However, high vehicle speeds are not desirable for pedestrians who have to cross urban arterials. In particular, pedestrians can be highly vulnerable at unsignalized, marked crosswalks where pedestrians have the right of way but where drivers' yield rates are significantly lower than at signalized intersections.

Walking is encouraged by many transportation agencies as a sustainable mode that contributes to livable downtowns. Since pedestrians are the most vulnerable road users, safe and comfortable crosswalks are essential to ensure that pedestrian travel becomes an appealing alternative. In this context, the goal of this research is to study the traffic and vehicle trajectory factors that affect crosswalk law compliance and stopping distance from the crosswalk.

This research examines traffic and trajectory factors that explain whether a driver complies with the Oregon pedestrian law. Data from detailed video records (several cameras at different heights) were utilized to analyze driver and vehicle trajectories up to 200 meters (650 feet) upstream of a crosswalk with a high record of pedestrian law violations.

The modeling results indicate that speed and headway changes, as well as driving trajectory before reaching the crosswalk, are the most significant variables to predict crosswalk law compliance and stopping distance. The results of this research suggest that treatments or driver notifications that discourage accelerating towards the crosswalk would be most useful to increase compliance.

Additionally, novel results indicate that vehicle origin and stopping at upstream traffic lights affect compliance rates. Drivers who are coming from a freeway or do not stop at an upstream traffic light are more likely to be less compliant and stop closer to the crosswalk. In addition, changes in vehicle speed and headways are the most significant variables to predict pedestrian crosswalk law compliance and stopping behavior.

This is the first research effort to analyze crosswalk stopping distance; it is notable that the variables that explain crosswalk compliance rates are also useful to explain stopping distance. Results also indicate that drivers are more likely to comply with the pedestrian law if the pedestrian stopped while crossing or had to speed up in response to approaching vehicles. Drivers of SUV/pickups tend to comply less than smaller passenger vehicles. 


\subsection{MOTIVATION}

Walking is encouraged by many transportation agencies as a sustainable mode that contributes to livable and healthy downtowns. The need to provide adequate pedestrian facilities has recently gained recognition in the United States as more cities and states aim to provide livable and walkable communities. Pedestrian safety is a necessary condition to sustain and foster more walking in urban areas.

Traffic laws and regulations should provide a legal framework that protects pedestrians when they are most vulnerable. In the U.S., state laws typically regulate traffic safety. The majority of states require drivers to yield or slow down for pedestrians. In Oregon, the law is stronger because drivers must stop for pedestrians as soon as they move onto the roadway in a crosswalk with the intent to proceed (NCLS, 2015). In addition, in Oregon state law determines that there is a crosswalk at every intersection with or without a marked crosswalk (i.e., for the state law there is a crosswalk at an intersection even if there is no zebra crossing). Furthermore, Oregon Revised Statutes (ORS) 811.028 requires that a driver, before crossing a crosswalk, stop and remain stopped for pedestrians until the pedestrians have cleared the lane in which the vehicle is traveling and the next lane (ORS, 2011). The area determined by the vehicle lane and the next lane is called the safety buffer. If a pedestrian is in the safety buffer when the vehicle enters the crosswalk the driver may be cited for a fine over \$260. Pamphlets from the Oregon Department of Transportation (ODOT) Safety Division illustrate the "safety buffer" concept (see Figure 1).

A contentious issue is the definition of the circumstances that delineate when a pedestrian is in the crosswalk. In 2011, to increase pedestrians' legal protection, it was added to ORS 811.028 that “... a pedestrian is crossing the roadway in a crosswalk when any part or extension of the pedestrian, including but not limited to any part of the pedestrian's body, wheelchair, cane, crutch or bicycle, moves onto the roadway in a crosswalk with the intent to proceed.” Hence, vehicles must stop for pedestrians as soon as they move onto the roadway in a crosswalk with the intent to proceed. The law further suggests that when stopping for a pedestrian on a multilane road, a driver should stop 30 feet before the crosswalk to avoid blocking the sight of drivers in other lanes (i.e., to reduce the risk of multithread crashes). Italics have been added to the word should because the Oregon law is clear to indicate that the driver must stop when a pedestrian is in the safety buffer, but the law does not specify a stopping distance from the crosswalk; 30 feet is a recommendation that is not enforceable by the traffic police. 


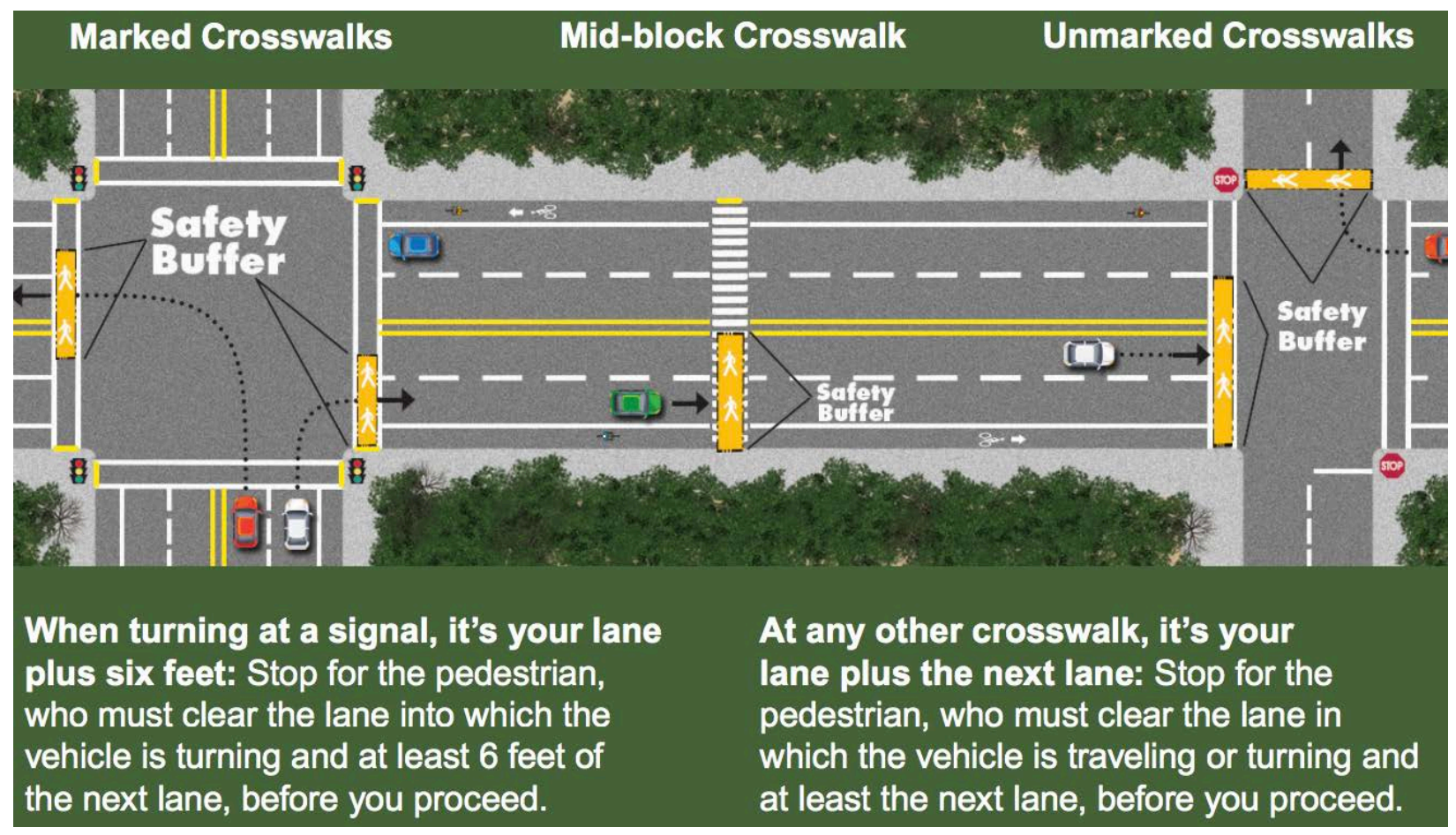

Figure 1. Illustration of the "safety buffer" concept (ODOT, 2015)

Pedestrians also have duties, such as obeying traffic signals and crossing the street only utilizing marked crosswalks and/or at intersections. In Oregon, a crosswalk exists at any public street intersection, whether marked with paint or unmarked (ORS 801.220). In addition, pedestrians must exercise due care and walk safely. According to ORS 811.005 (2011), "None of the provisions of the vehicle code relieve a pedestrian from the duty to exercise due care or relieve a driver from the duty to exercise due care concerning pedestrians.”

Enforcement of traffic laws and regulations is another important element to guarantee safe pedestrian activity in a roadway environment. For example, Portland's Bureau of Transportation (PBOT), in conjunction with the Portland Police Traffic Division, periodically conducts "crosswalk education and enforcement actions." One or more pedestrian decoys are utilized at locations that have marked or unmarked crosswalks and police officers control whether drivers show non-compliance of Oregon's traffic laws; the pedestrian decoys follow the law and exercise due care. Crosswalk enforcement actions are conducted approximately once each month (PBOT, 2015). According to PBOT statistics, over 60\% of the citations are written for Oregon's crosswalk law (ORS 811.028) violations and are caused by "failure to stop and stay stopped for a pedestrian." Other common driver violations include speeding, use of a cell phone, passing a stopped vehicle at a crosswalk, and no driver's license, plates or proof of insurance. The most common pedestrian violation is jaywalking (PBOT, 2015).

The high number of violations during enforcement actions - sometimes over 20 per hour - is startling given that enforcement actions are announced. Crosswalk education and enforcement actions are typically announced in the media days before and also with a red flag, a temporary sign, and cones placed one or two blocks ahead of the crosswalk during the enforcement action (BikePortland, 2015). The temporary sign reads "Pedestrian Crosswalk Enforcement Ahead." 
Enforcement actions typically take place in locations with a high number of pedestrian complaints or with a record of recent pedestrian fatalities and/or injuries.

This research focuses on the study of the factors that can explain the high number of violations of pedestrian crosswalk laws. More specifically, this research answers two research questions: (1) What are the factors that affect driver non-compliance? and (2) What are the factors that affect driver stopping distance? To answer these questions, detailed video records (several cameras at different heights) were utilized to analyze driver and vehicle trajectories up to 200 meters (650 feet) upstream of crosswalks with a high record of pedestrian crosswalk law violations. This study tests whether more detailed traffic and trajectory variables can be used to explain drivers' noncompliance (i.e., the null hypothesis states that detailed trajectory and traffic variables are not significant or not do not explain drivers' non-compliance). This research only analyzes events where pedestrians fully comply with the law; a few events with aggressive pedestrians are excluded from the study.

The next section provides a brief literature review, and the following section describes the data collection process and study site. Binary logistic and ordered logistic regression models are developed to elucidate the factors that affect non-compliance and stopping distance. The most dangerous events are later summarized and described. The research ends with a discussion of key results and conclusions. 


\subsection{PROBLEM/BACKGROUND}

\subsection{PEDESTRIAN SAFETY}

In the U.S., pedestrian crashes are a serious safety issue. In 2013, there were 4,735 pedestrians killed in traffic crashes; pedestrian fatalities accounted for $14 \%$ of all U.S. traffic fatalities and fatalities increased 15\% between 2009 and 2013 (NHTSA, 2015). The majority of fatalities and injuries are the result of crashes where the point of impact is the front of the vehicle, but the undisputable causes of the fatal crashes are not easy to disentangle from the recorded data (NHTSA, 2014).

There have been many studies trying to analyze crosswalk law compliance. Britt et al. (1995) observed that approximately 80\% of drivers failed to stop for pedestrians in Seattle. The authors evaluated a four-year safety campaign in Seattle and concluded that more enforcement seemed to produce a slight to null improvement in compliance. A recent meta-analysis by Phillips et al. (2011) suggests that safety campaigns are likely to be more effective in the short-term if they are accompanied by enforcement and personal communications. Personal communication, unlike mass media campaigns, entails lessons or seminars delivered in person or two-way discussions with a peer or group discussions. A review of pedestrian safety research suggests that it is nearly impossible to quantify the impact of enforcement or education campaigns on pedestrian safety or drivers' behavior (Campbell et al., 2004).

Studies that attempt to quantify the impact of traffic variables or engineering design features on drivers' behavior at crosswalks have been more successful. Advance yield markings and prompt signs are likely to reduce pedestrian-vehicle conflicts (Van Houten, 1988). In this particular research effort, signs constructed to prompt drivers to stop at a specific location for pedestrians read "STOP HERE FOR PEDESTRIANS" and had an arrow pointing down toward the road at an angle of 45 degrees below the horizontal. When the vehicle speed is lower, a driver is more likely to stop for a pedestrian (Katz et al., 1975). On the other hand, wider roads are associated with higher speeds and more crashes; there is a strong relationship between vehicle-pedestrian crash severity and speed (Gårder, 2004). A vehicle that can safely stop when a pedestrian enters the crosswalk is more likely to yield, especially if the required deceleration rate is less than $10 \mathrm{ft} / \mathrm{s}^{2}$ (Schroeder \& Rouphail, 2011). A vehicle that is a part of a platoon is more likely to yield than a vehicle that is not a part of a platoon, and drivers are more likely to yield when pedestrians are aggressive (Schroeder \& Rouphail, 2011). Some treatments such as raised medians, traffic and pedestrian signals, curb extensions, raised islands, tighter turn radii, and adequate nighttime lighting can help reduce crash frequency or severity (Meat et al., 2014). Some of these treatments are particularly effective on multilane or high-speed arterial roads.

\subsection{PEDESTRIAN CROSSWALK LAWS}

Regarding research that deals with pedestrian crosswalk laws, the focus of this research, two papers stand out. Kim et al. (2008) studied a new, stronger law introduced in Hawaii in 2005 that requires drivers to stop and yield to pedestrians at crosswalks. Before 2005, drivers had the option of yielding or slowing down at a crosswalk and had to stop only when necessary. Data was collected for one hour at 30 locations, and logistic regression models predicting the likelihood of violation of the crosswalk laws by drivers found that senior drivers had higher compliance rates. 
The highest non-compliance rate, drivers not stopping for pedestrians on the crosswalk, took place at unsignalized, midblock crosswalks. In this study, high non-compliance was also associated with hotel districts, office areas and high-density residential areas. Kweon et al. (2009) utilized the Fatality Analysis Reporting System database to analyze whether pedestrian laws that require drivers to yield to pedestrians in crosswalks had an effect on pedestrian safety on low-speed roads. The study found no statistically significant reduction in pedestrian-involved fatal crashes, but the authors attributed this result to the omission of high-quality exposure data.

This research also studies factors associated with the likelihood of violation of the crosswalk laws by drivers. However, unlike previous research efforts (Kim et al., 2008; Schroeder \& Rouphail, 2011), this study focuses mostly on drivers and the inclusion of novel traffic variables that capture driver trajectory and behavior before arriving to the crosswalk area (i.e., speed change, headways, origin, stopping at upstream traffic lights, etc.); trajectory and upstream traffic variables are not included in previous studies. In addition, this study also models stopping distance; previous research efforts have not modeled this dependent variable. Finally, the data collection environment is different from other studies. This research analyzes crosswalks in a multilane, one-way street in a downtown area with mixed commercial, office, residential and educational land uses. The next section describes the data collection process. 


\subsection{DATA COLLECTION}

\subsection{STUDY SITE}

The study site selection process was guided by two considerations: (a) finding a site with a high number of crosswalk law violations and (b) finding a site where it was possible to readily collect detailed vehicle trajectory and traffic data. For the former consideration, the research team utilized statistics collected by PBOT in the last 10 years; for the latter consideration, the research team conducted site visits to analyze the location of video recording equipment.

The location chosen for this research was the intersection of SW 4th Avenue and SW College Street (see crosswalk in figures 2 and 3). At this location, an enforcement action resulted in 40 traffic law violations in a period of two hours, between 11 a.m. and 1 p.m. Out of the 40 violations, the vast majority (36 violations) were the result of failing to stop for pedestrians. Another advantage of this location was that the research team had access to a university building rooftop to install video recording equipment. From this rooftop, it was possible to record video to track detailed vehicle trajectories up to 200 meters (650 feet) upstream of the crosswalk at SW 4th and College. Hence, it was possible to see whether the vehicles arrived from SW 4th Avenue, the Interstate 405 (freeway) off-ramp, or the side street (SW Lincoln). At this site, it was also possible to complement the rooftop camera with two cameras placed on lampposts. The first lamppost camera was located near SW 4th and College to capture pedestrian and driver behavior at both crosswalks. The second lamppost camera was located at SW 4th and Lincoln (one block upstream) to capture events at this signalized intersection. SW 4th is a one-way, multilane, minor arterial with average weekday traffic of 11,292 vehicles per day in 2010 (PBOT, 2014).

Vehicles that arrive at the study intersection come from three origins: Interstate 405 (I-405), minor arterial SW 4th Avenue, and local SW Lincoln Street. There are signalized intersections one block upstream and downstream of the study location (see Figure 2). On SW 4th there are three central lanes for traffic and two outer lanes (one on the right and on the left) for parking. However, parking is not allowed 40 feet before the crosswalk because there are curb extensions and ramps for vehicle access to office buildings (east/right side) and a gas station exit (west/left side). At the study site, there are no traffic signals but there are two crosswalks with a continental design pattern (see Figure 3). For the sake of simplicity, herein, the upstream crosswalk and downstream crosswalk will be denoted CW1 and CW2, respectively, and for the sake of clarity speed lines for CW2 are not shown in Figure 3.

Along SW $4^{\text {th }}$ there are no in-street signs to encourage yielding and there is no advance stop/yield line. At each crosswalk there is a bulb-out, and pedestrians utilizing a crosswalk only have to cross three lanes of traffic instead of five lanes. There are several office buildings near the crosswalks. Based on video observation, the majority of pedestrian traffic goes to or comes from the University Building and/or City of Portland facilities and office buildings located on the east (right) side of SW 4th. Around lunchtime, the majority of pedestrian traffic utilizes the crosswalks to access the food cart area on the west (left) side of SW 4th. As shown in Figure 3, the distance between CW1 and the upstream intersection at SW Lincoln is approximately 120 meters or 400 feet; this figure can be obtained by summing the partial distances. The distance between CW2 and the downstream traffic signal at SW 4th and SW Hall is approximately 80 meters (260 feet). 


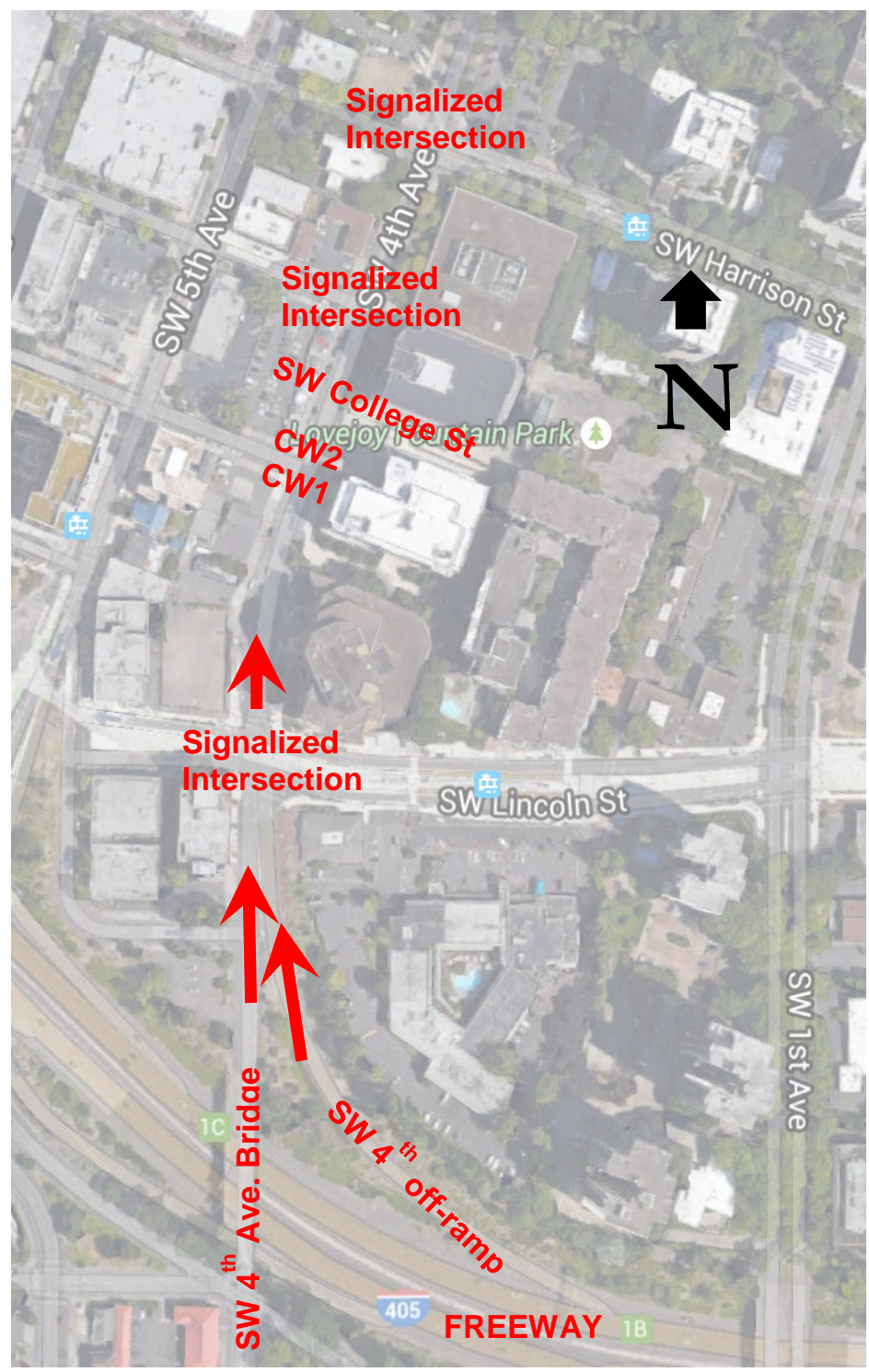

Figure 2 : Aerial view of the study site 


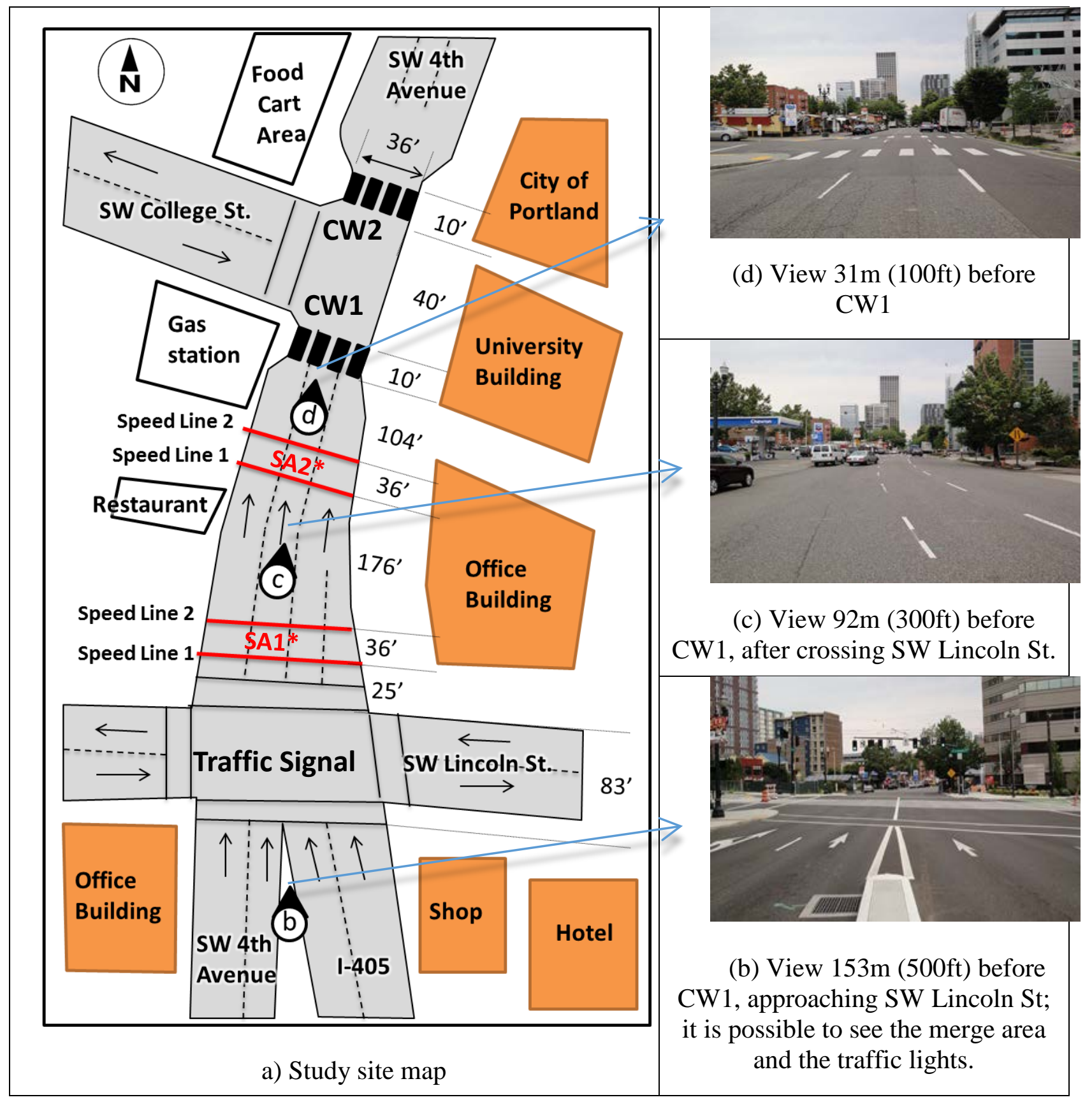

Figure 3 : Schematic view of the study site, distances (in feet) and three drivers' perspectives

*For the sake of clarity, only Speed Areas 1 and 2 (SA1 and SA2) for CW1 are drawn 


\subsection{DATA SUMMARY}

At the time of the data collection, SW $4^{\text {th }}$ Avenue traffic received the largest proportion of green time (approximately 65\% of the cycle) at the upstream and downstream signalized intersections. The pedestrian and vehicle datasets were collected in March on a day when the sky was clear and there was no rain (i.e., no visibility problems). The datasets were collected during the late morning and early afternoon, from 11:30 a.m. to 12:30 p.m. During the data collection period, the following numbers describe traffic flows, vehicle origin and pedestrian flows:

- Overall, 684 vehicles traveled on SW 4th Avenue across the study site:

o 160 vehicles came from I-405 (23\%),

o 341 vehicles came from SW 4th (50\%), and

o 183 vehicles came from SW Lincoln Street (27\%).

- The majority of the vehicles were passenger cars:

o 397 passenger cars (58\%),

o 232 SUVs/pickup trucks (34\%), and

o 55 other types including buses and commercial vehicles (8\%).

- Overall, 531 pedestrians utilized the crosswalks:

o 133 pedestrians utilized CW1 (25\%),

o 398 pedestrians utilized CW2 (75\%),

o 266 pedestrians crossed the road in the eastbound direction (50\%), and

o 265 pedestrians crossed the road in the westbound direction (50\%). 


\subsection{DATA PROCESSING AND DEFINITIONS}

\subsection{DATA PROCESSING}

This research utilized detailed video records from several video cameras situated at different locations and heights to capture the behavior of drivers and pedestrians before, during and after crossing the crosswalk. Data processing was a very demanding effort in terms of staff hours. It took several weeks to process all of the traffic data and complete the data quality control checks. A video observation protocol was developed and data quality was monitored throughout the data processing task.

The day before the data collection, the pavement was marked at predetermined distances. Figure 3 shows the lines used to determine speed after the Lincoln Street Speed Area 1 (SA1) and before College Street Speed Area 2 (SA2). In addition, other lines were drawn to estimate the speed and distance of the vehicles when a pedestrian entered the crosswalk. The video data quality was enough to accurately estimate speeds and headways. Vehicles speeds are measured from the video, with 10 frames per second. Researchers were able to stop or advance the video in 1/10-second increments.

The data processing involved several steps: (i) video was analyzed to measure pedestrian and vehicle volumes and speeds; (ii) video was analyzed to record the time when there was a pedestrian-vehicle interaction; (iii) for each event recorded in step (ii), each graduate student (independently) recorded detailed information about the vehicle trajectory, traffic conditions and pedestrian behavior; and (iv) for quality assurance each pedestrian-vehicle event collected in (iii) was compared. In a few occasions, if there was any discrepancy both graduate students reanalyzed the video until there was complete agreement. Overall, there was a very high level of agreement the first time the data was processed independently.

The final models only include compliance and non-compliance events where the pedestrian exercised prudence and due care as requested by the law. As in previous studies (e.g., Bennet et al., 2014), this condition is met if the pedestrian entered the crosswalk area when the approaching vehicle was located at a distance equal to or larger than the dilemma zone for traffic signals. The total stopping time as defined by the Institute of Transportation Engineers (ITE, 1999) for traffic signals is:

$$
Y=t+\frac{v}{(2 a+2 G g)}
$$

Where $\quad \begin{array}{cl}Y & =\text { Total time (s or seconds) } \\ v & =\text { Vehicle speed }(\mathrm{ft} / \mathrm{s}) \\ t & =\text { Reaction time }(\mathrm{s} \text { or seconds) } \\ a & =\text { Deceleration rate }\left(\mathrm{ft} / \mathrm{s}^{2}\right) \\ G & =\text { Roadway grade }(\text { percent) } \\ g & =\text { Gravity acceleration }\left(\mathrm{ft} / \mathrm{s}^{2}\right)\end{array}$


The operational reaction time of an average driver in an urban area is assumed to be one second and maximum deceleration rate is assumed to be $10 \mathrm{ft} . / \mathrm{s}^{2}$ or $6.8 \mathrm{mph}$. The safe stopping distance (SSD) is obtained by multiplying $Y$ and $v$, time and speed. For a speed of 25 miles per hour (40.2 $\mathrm{km} / \mathrm{h}$ ) a vehicle SSD is 104 feet $(31.7 \mathrm{~m})$; for a speed of 30 miles per hour (48.3 km/h), a vehicle SSD is 141 feet $(42.9 \mathrm{~m})$. Note that in this study $G=0$ and with the one-second reaction time the SSD can be calculated as $v+\frac{v^{2}}{2 a}$.

Pavement markings were utilized to determine vehicle location and speed when the pedestrian entered the crosswalk. A speed pilot data collection study showed that the speed distribution $85^{\text {th }}$ percentile was approximately $27.5 \mathrm{mph}$. The stopping distance for a speed of $27.5 \mathrm{mph}$ is $122 \mathrm{feet}$, and the location of SA2 was chosen so that the center of SA2 is 122 feet away from CW1. Likewise, lines were drawn 122 feet before CW2. For the sake of clarity, lines SA1 and SA2 for CW2 are not shown in Figure 3. Note that the ITE formula is very conservative, and modern vehicles can safely break at deceleration rates much higher than $10 \mathrm{ft} / \mathrm{s}^{2}$ (NCHRP, 1997). Furthermore, the speed limit on SW 4th is $20 \mathrm{mph}$, which is less than the utilized $85^{\text {th }}$ speed percentile. The $85^{\text {th }}$ speed percentile is utilized because ODOT recommends it to set speed limits that increase user compliance (ODOT, 2014). The median and average speeds are approximately 22 mph (see tables in the Appendix).

To determine if there was a violation of the crosswalk law, the diagrams presented in Figure 1 were followed as well as the text of the law ORS 811.028. A detailed set of instructions was developed to ensure consistency among data processors and data recorders. ORS 811.028 is violated when the driver does not stop for a pedestrian, as shown in Figure 1; ODOT recommends that a vehicle stops 30 feet before the crosswalk in multilane arterials. To study if vehicles that comply with the law were also complying with the 30-feet recommendation, the stopping distance of compliant vehicles was also recorded. In addition, Oregon law states that pedestrians must exercise due care and walk safely (ORS 811.005).

Summarizing, the following conditions were required to have a valid pedestrian-vehicle event and to standardize the data processing:

i. The vehicle crossed CW1 and CW2 (i.e., the vehicle did not turn left at College Street).

ii. If a driver had a compliance event at CW1, any posterior non-compliance event at CW2 was not included in the dataset.

iii. The vehicle did not exit from a mid-block location (i.e., gas station or building between College and Lincoln).

iv. A pedestrian entered CW1 or CW2 when an approaching vehicle was at least 122 feet away.

v. The pedestrian correctly utilized the crosswalk and followed the law (i.e., no partial or full jaywalking).

Conditions (i) and (ii) are necessary to separate any interaction effect between CW1 and CW2. Condition (iii) is necessary to estimate the impact of speed and upstream traffic conditions on compliance rates. Conditions (iv) and (v) are necessary to study only events where the pedestrians fully comply with Oregon law (i.e., the pedestrian is walking safely and exercising due care). The focus of this study is on driver behavior; hence, we are excluding a few events where pedestrians may have been aggressive or jaywalked. 
After applying conditions (i) to (v), several driver-pedestrian interactions were removed from the dataset. A total of 73 ORS 811.028 non-compliance events were observed after the data was analyzed, processed and filtered, as described in this section; 43 drivers complied with the law and stopped for pedestrians between 0 and 30 feet from the crosswalk. There were six observations where the drivers stopped at a distance that exceeded 30 feet. The ratio of compliant over noncompliant events was approximately the same for both crosswalks. The reader is reminded that there is no "Stop Here for Pedestrians" in-street sign or line marked on the pavement before either CW1 or CW2. In all of the modeling results presented in the next section, 116 observations were utilized to estimate the coefficients.

\subsection{DEFINITIONS}

Table 1 presents a data dictionary of the independent variables utilized in both models. Only events that comply with conditions (i) to (v), detailed in the previous section, were included in the models. The acronym CIA stands for "Crosswalk Influence Area" and is defined as the area, adjacent to the curb and with a different texture, that lets visually impaired pedestrians quickly identify the presence of a crosswalk.

From the video it was not possible to accurately determine drivers' personal characteristics, such as gender or age group. Data processors had a $5 \%$ or higher rate of disagreement or more than $5 \%$ of observations that were classified as "unable to accurately determine gender/age group." Hence, driver demographic variables are not included in the models. Some contributing factors associated with drivers' risk of accident (i.e., driver under the influence of alcohol) were not observable either. Likewise, attitudes towards risk taking and/or aggressive personality characteristics are not observable unless the driver manifested them in a crosswalk non-compliance action. In Table 1, any references to "vehicle/driver" or "pedestrian" are in relation to the vehicle or pedestrian that were involved in a compliance or non-compliance event. Unless stated otherwise, the timing of any data point is when the pedestrian entered the crosswalk. 
Table 1. Data Dictionary for Binary Logistic and Ordered Logistic Regression Models

\begin{tabular}{|c|c|c|}
\hline Dependent Variables & Type & Description \\
\hline Compliance & Binary & 1 if a vehicle complied with ORS 811.028, 0 otherwise. \\
\hline Stopping Distance & Ordinal & $\begin{array}{l}\text { Distance between stopped vehicle and crosswalk: } 0 \text { if vehicle did NOT } \\
\text { stop, } 1=\text { if stopped 0-10' from crosswalk, } 2=\text { if stopped } 10-20 \text { ', } 3=\text { if } \\
\text { stopped } 20-30 \text { ', } 4=\text { if stopped } 30-40 \text { '. }\end{array}$ \\
\hline \multicolumn{3}{|l|}{ Pedestrian Variables } \\
\hline Pedestrian Speed & Continuous & Pedestrian crossing speed between curbs (feet per second). \\
\hline Ped Direction & Binary & 1 if eastbound. \\
\hline Ped Lane & Binary & $\begin{array}{l}\text { Ped location when the non-compliance took place, } 1=\text { left lane, } 2= \\
\text { center lane, } 3=\text { right lane. It was modeled as a dummy variable. }\end{array}$ \\
\hline Disturbance & Binary & 1 if the pedestrian had to stop or speed up significantly. \\
\hline CIA Time & Continuous & $\begin{array}{l}\text { Pedestrian time (seconds) at the CIA (crosswalk influence area) before } \\
\text { crossing. }\end{array}$ \\
\hline Peds in CIA & Integer & Number of pedestrians in CIA when the event took place. \\
\hline \multicolumn{3}{|l|}{ Driver/vehicle Variables } \\
\hline Origin I-405 & Binary & Vehicle comes from I-405. \\
\hline Origin SW 4th Avenue & Binary & Vehicle comes from SW $4^{\text {th }}$. \\
\hline Vehicle Type & Binary & $\begin{array}{l}\text { Binary variables to distinguish passenger cars, light duty trucks, vans, } \\
\text { medium-duty trucks, and transit buses. }\end{array}$ \\
\hline Lincoln Red Light & Binary & 1 if the vehicle stopped at the red light at SW Lincoln. \\
\hline Vehicle Speed & Continuous & Vehicle speed when pedestrian enters the crosswalk. \\
\hline Speed1 & Continuous & Vehicle speed at SA1. \\
\hline Speed2 & Continuous & Vehicle speed at SA2. \\
\hline Speed Change & Continuous & Difference: Speed2 - Speed1. \\
\hline Platoon1 & Binary & 1 if the vehicle is part of a platoon at SA1. \\
\hline Platoon2 & Binary & 1 if the vehicle is part of a platoon at SA2. \\
\hline Vehicle Headway & Continuous & Time between vehicles when pedestrian enters the crosswalk. \\
\hline Ups. Headway1 & Continuous & Time between vehicle and (next) upstream vehicle at SA1. \\
\hline
\end{tabular}




\begin{tabular}{|c|c|c|}
\hline Ups. Headway2 & Continuous & Time between vehicle and (next) upstream vehicle at SA2. \\
\hline Ups. Headway Change & Continuous & Difference: Ups. Headway2 - Ups. Headway1. \\
\hline Dow. Headway1 & Continuous & Time between vehicle and (next) downstream vehicle at SA1. \\
\hline Dow. Headway2 & Continuous & Time between vehicle and (next) downstream vehicle at SA2. \\
\hline Dow. Headway Change & Continuous & Difference: Dow. Headway2 - Dow. Headway1. \\
\hline Lane Change & Binary & 1 if the vehicle changed lanes between Lincoln and College. \\
\hline Left Turn Waiting & Binary & 1 if there is another vehicle waiting to turn left at College. \\
\hline Vehicle Lane & Binary & $\begin{array}{l}\text { A binary variable for each lane; lane that the vehicle used to enter the } \\
\text { crosswalk. }\end{array}$ \\
\hline Distance & Continuous & Distance from crosswalk. \\
\hline Adjacent Stopped & Binary & 1 if a vehicle in an adjacent lane stops for a pedestrian. \\
\hline \multicolumn{3}{|c|}{ Roadway and Crosswalk Variables } \\
\hline Crosswalk & Binary & 1 if non-compliance took place at CW1. \\
\hline Num. Vehicles & Integer & Number of vehicles between Lincoln and College. \\
\hline Num. Bicycles & Integer & Number of bicycles between Lincoln and College. \\
\hline Num. Peds. & Integer & Number of pedestrians in the crosswalk plus CIAs. \\
\hline Num. Peds. in CIA & Integer & Number of pedestrians in the CIAs. \\
\hline Visual Obstruction & Binary & $\begin{array}{l}1 \text { if there was a visual obstruction (i.e., another vehicle) in the line of } \\
\text { sight between the driver and the pedestrian when the pedestrian entered } \\
\text { the crosswalk. }\end{array}$ \\
\hline
\end{tabular}




\subsection{BINARY LOGISTIC MODELING RESULTS}

Assuming that pedestrians comply with the law and exercise due care, this research aims to answer two questions: (1) What are the factors that affect driver non-compliance? and (2) What are the factors that affect driver stopping distance? To answer these research questions, two models were developed: (1) a binary logistic regression model where the dependent variable is compliance (i.e., whether a vehicle followed the ORS 811.028 law) and (2) an ordered logistic regression model where the dependent variable is stopping distance. Probit models were also developed, but the logit model presented better results in terms of fit. The literature review indicates that speed is an important variable to explain drivers' non-compliance. This study tests whether more detailed traffic and trajectory variables can be used to explain drivers' non-compliance (i.e., the null hypothesis states that detailed trajectory and traffic variables do not explain drivers' noncompliance or that their estimated coefficients are zero).

\subsection{BINARY MODEL RESULTS}

This subsection presents the results of a model where the dependent variable is compliance (i.e., whether a vehicle followed ORS 811.028); the independent variables are all the variables listed in Table 1 . The data collection process selected only events where the drivers had the option to safely stop and comply with the pedestrian law. Hence, a binary logistic regression model where the dependent variable is to comply $(Y=1)$ or not comply $(Y=0)$ is warranted. Binary logistic and probit models were explored; the results were conceptually similar but logitic models results were slightly superior in terms of the Akaike information criterion, or AIC.

A model specification was selected dropping variables that were not significant and utilizing a backwards stepwise selection procedure based on variable significance and AIC values. Different model specifications were tested (e.g., including all of the speeds and headways vs. including speed and headway differences or combining differences and actual measurements). The final model is shown in Table 2. The independent variables are sorted by P-value, from lowest to highest. If variables from the model are removed one at a time, ceteris paribus, it is possible to get a sense of the contribution of each variable to the explanatory power of the model. Table 3 shows the change in log-likelihood value and variables are sorted in terms of their explanatory power. The ordering in Table 3 is almost the same as the ordering in Table 2 except for the variables "Peds in CIA" and "Origin SW 4th Avenue" that swapped positions.

The results presented in Table 2 and Table 3 show that "Speed Change," or whether the driver speeds up or slows down, is by far the strongest predictor of the pedestrian law compliance. Drivers who increase their speed between speed areas 1 and 2 (SA1 and SA2) are less likely to comply with the crosswalk law. The reader is reminded that SA2 is approximately 122 feet before a crosswalk, hence, the speed change variable does not include the segment where the driver or vehicle are typically decelerating as they approach the crosswalk. In the models, "Speed Change" was a variable that prevailed over the actual speed at SA2 or the speed of the vehicle when the pedestrian entered the crosswalk. 
Table 2. Final Compliance Model

\begin{tabular}{|l|r|r|r|r|l|}
\hline \multicolumn{1}{|c|}{ Variable } & \multicolumn{1}{c|}{ Coeff. } & \multicolumn{1}{c|}{ Std.Err. } & \multicolumn{1}{c|}{ t-value } & \multicolumn{1}{c|}{ P-value } & Signif. \\
\hline Intercept & -3.882 & 0.878 & -4.422 & $9.78 \mathrm{E}-06$ & $* * *$ \\
\hline Speed Change & -0.187 & 0.050 & -3.740 & $1.84 \mathrm{E}-04$ & $* * *$ \\
\hline Down. Headway Change & 0.151 & 0.047 & 3.223 & $1.27 \mathrm{E}-03$ & $* *$ \\
\hline Disturbance & 4.006 & 1.331 & 3.011 & $2.61 \mathrm{E}-03$ & $* *$ \\
\hline Peds in CIA & 0.701 & 0.296 & 2.365 & $1.80 \mathrm{E}-02$ & $*$ \\
\hline Origin SW 4 ${ }^{\text {th }}$ Avenue & 1.431 & 0.610 & 2.347 & $1.89 \mathrm{E}-02$ & $*$ \\
\hline Lincoln Red Light & 1.315 & 0.630 & 2.088 & $3.68 \mathrm{E}-02$ & $*$ \\
\hline SUV-Pickup & -1.177 & 0.670 & -1.690 & $9.10 \mathrm{E}-02$ &. \\
\hline Adjacent Stopped & 1.013 & 0.611 & 1.658 & $9.73 \mathrm{E}-02$ & $*$ \\
\hline
\end{tabular}

Codes significance: “”” when $\mathrm{p}<0.10$; “*” when $\mathrm{p}<0.05$; “**” when $\mathrm{p}<0.01$; “**** when $\mathrm{p}<0.001$

Table 3. Compliance Model - Ceteris Paribus Log-likelihood Change

\begin{tabular}{|l|r|}
\hline \multicolumn{1}{|c|}{ Variable } & \multicolumn{1}{c|}{$\Delta \mathbf{L L}$} \\
\hline Speed Change & 10.01 \\
\hline Down. Headway Change & 6.56 \\
\hline Disturbance & 5.54 \\
\hline Origin SW 4 ${ }^{\text {th }}$ Ave & 3.06 \\
\hline Peds in CIA & 2.71 \\
\hline Lincoln Red Light & 2.37 \\
\hline SUV-Pickup & 1.57 \\
\hline Adjacent Stopped & 1.48 \\
\hline
\end{tabular}


The second variable in terms of importance, "Down. Headway Change," indicates that when the headway between the vehicle (that is part of the pedestrian-driver interaction event) and the vehicle ahead (downstream) increases, then the vehicle is more likely to comply with the pedestrian law. Hence, if the platoon of vehicles becomes more compact, the driver is less likely to comply with the pedestrian law. "Down. Headway Change" was a variable that prevailed over the actual headway at SA2 or when the pedestrian entered the crosswalk.

The third variable, "Disturbance," indicates that a driver is more likely to stop if the pedestrian suddenly reduces or increases his/her walking speed. Disturbance is a function of the comparison of the pedestrian speed when the vehicle is located 60 feet or more and when the vehicle is located 60 feet or less. If the pedestrian speed changed by more than $50 \%$ (plus or minus) then it was coded that the pedestrian was "disturbed." This variable was coded 1 when the pedestrian looking at the oncoming vehicle decided to stop or significantly increase walking speed to avoid a potential crash. Perhaps drivers more easily notice a significant change in pedestrian speed and observing this "pedestrian anxiety or distress" leads to higher compliance with the law.

The fourth variable, "Peds in CIA," indicates that a driver is more likely to stop if there is a group of pedestrians entering the crosswalk or about to enter the crosswalk. It is likely that more pedestrians are easier to see and/or that drivers feel more compelled to yield when there are more pedestrians involved in the events.

The fifth variable, "Origin SW $4^{\text {th }}$ Avenue," indicates that a driver is more likely to stop if the pedestrian origin is SW $4^{\text {th }}$. If this variable is removed, then the variable "Origin I-405" with a negative sign enters the model (all other variables remain). This indicates that drivers who are coming from I-405 may not have enough time to adjust to the new "urban" and pedestrian environment. There are no speed limit or pedestrian signs before the crosswalks. In addition, three lanes of traffic may provide clues about a vehicle-dominant environment. Previous research efforts have indicated that drivers who have driven at high speeds for a prolonged period are more likely to underestimate their traveling speed; this phenomenon is usually called "speed adaptation" (NCHRPS, 2011).

The sixth variable, "Lincoln Red Light," reinforces this interpretation. Vehicles that are stopped at the upstream traffic light are more likely to comply with the crosswalk law. It is possible that the red traffic light indication is giving the drivers more time to adjust to urban driving conditions and the presence of pedestrians ahead.

The seventh variable, "SUV-Pickup," indicates that drivers of larger vehicles are less likely to comply with the crosswalk law. However, vehicle size is not likely to be the direct factor affecting non-compliance; as a counterexample, public transportation (bus) drivers always complied with the law and stopped far away from the crosswalk. The final and eighth variable, "Adjacent Stopped," indicates that drivers are more likely to comply with the law if another driver has already complied. This result agrees with previous research efforts (e.g., Schroeder \& Rouphail, 2011), but in this case is a multilane, one-way street.

\subsection{NEAR CROSSWALK VARIABLES}

To more easily compare the results to previous studies, the results of a model constrained to have only variables that are measured between the Speed Area 2 (SA2, approximately 122 feet from the crosswalk) and the crosswalk are shown in Table 4. As expected, vehicle speed, headway, number 
of pedestrians in the CIA, and pedestrian disturbance are significant variables, and their signs are intuitive and have the same interpretation as before. In addition, a variable "Visual Obstruction" is significant.

When comparing AIC values for the model in Table 2 (AIC = 107.33) and the model in Table 4 $($ AIC $=122.65)$, it is possible to observe a clear loss of information and predictive value. The relative likelihood of the model in Table 4 is $0.05 \%$ (i.e., the second model is $0.05 \%$ as probable to minimize information loss when compared to the model presented in Table 2). We can safely conclude that the addition of trajectory and upstream traffic variables (stopping at a traffic light, vehicle origin, speed upstream, headway upstream) are providing highly variable information to predict the compliance of the law.

Table 4. Final Compliance Model with only College Variables

\begin{tabular}{|l|r|r|r|r|l|}
\hline \multicolumn{1}{|c|}{ Variable } & \multicolumn{1}{c|}{ Coeff. } & \multicolumn{1}{c|}{ Std.Err. } & \multicolumn{1}{c|}{ t-value } & \multicolumn{1}{c|}{ P-value } & Signif. \\
\hline (intercept) & -1.305 & 0.907 & -1.438 & $1.50 \mathrm{E}-01$ & \\
\hline Num. Peds. in CIA & 0.828 & 0.292 & 2.837 & $4.55 \mathrm{E}-03$ & $* *$ \\
\hline Disturbance & 2.722 & 1.099 & 2.478 & $1.32 \mathrm{E}-02$ & $*$ \\
\hline Speed2 & -0.084 & 0.034 & -2.463 & $1.38 \mathrm{E}-02$ & $*$ \\
\hline Visual Obstruction & 1.031 & 0.519 & 1.989 & $4.68 \mathrm{E}-02$ & $*$ \\
\hline Dow. Headway2 & 0.071 & 0.042 & 1.704 & $8.85 \mathrm{E}-02$ & $*$ \\
\hline
\end{tabular}

Codes significance: “.” when $\mathrm{p}<0.10$; “*” when $\mathrm{p}<0.05$; “**”when $\mathrm{p}<0.01$

Summarizing, the model results reject the null hypothesis since the estimated coefficients for speed change and downstream headway change were not only highly significant but also the most important variables in terms of p-values and explanatory power. Also, in terms of AIC, a model with detailed traffic and trajectory variables clearly outperforms a model that includes only traffic speed or headway information near the crosswalk. Previous research efforts have indicated that approaching speed is a key factor to predict driver behavior; the presented research results do not contradict this finding. Approaching speed is indeed a significant and important factor, but the same can be said about other traffic and trajectory variables that measure headway/speed change, vehicle origin, and number of previous stops. However, the results suggest that speed and headway change are perhaps more important than speed/headway measured at only one point along the trajectory of the vehicle. 


\subsection{ORDERED LOGISTIC MODELING RESULTS}

This section presents the results of an ordered logistic regression model where the dependent variable is stopping distance from the crosswalk. Ordinal logistic regression models are suitable in this case because the dependent variable is categorical of an ordered nature. Stopping distances were grouped into several groups: (1) negative (i.e., vehicles that do not stop); (2) vehicles stopped between 0 and 10 feet from the crosswalk; (3) vehicles stopped between 10 and 20 feet from the crosswalk; (4) vehicles stopped between 20 and 30 feet from the crosswalk; and (5) vehicles stopped at a distance longer than 30 feet. A nested model where the first choice was whether to comply with the law and the second choice within "comply" was stopping distance was not supported by the data; hence, in this section only the results of the ordered logistic model are reported.

The independent variables are all the variables listed in Table 1. A model specification was selected, dropping variables that were not significant and utilizing a backwards stepwise selection procedure (based on the Akaike information criterion, or AIC). The final model is shown in Table 5. Most variables are significant at the $\mathrm{p}<0.05$ level, with the remainder being significant at the $\mathrm{p}<0.10$ level. The model also passed the test of parallel lines.

Most of the variables that were significant in the compliance model are also significant in this model and can be interpreted in a similar way: Speed Change, Down. Headway Change, Disturbance, Origin SW 4th Avenue, Peds in CIA, SUV-Pickup, and Lincoln Red Light. The model results indicate that the variables that are useful to predict compliance are also useful to predict stopping distance. In the final model shown in Table 5, it is possible to see that only one variable, "Adjacent Stopped," was dropped from the model shown in Table 2. Only one variable, "Visual Obstruction," was added to the model. The positive value of "Visual Obstruction" indicates that if there is a visual obstruction (another vehicle) in the line of sight between the driver and the pedestrian (when the pedestrian entered the crosswalk), then the driver is more likely to stop farther away from the crosswalk. This variable is correlated with presence of traffic on adjacent lanes. One possible interpretation is that the presence of adjacent traffic tends to make drivers more alert and/or ready to stop. 
Table 5. Final Distance Model

\begin{tabular}{|l|r|r|r|r|l|}
\hline \multicolumn{1}{|c|}{ Variable } & \multicolumn{1}{c|}{ Coeff. } & \multicolumn{1}{c|}{ Std.Err. } & \multicolumn{1}{c|}{ t-value } & \multicolumn{1}{c|}{ P-value } & Signif. \\
\hline Speed Change & -0.115 & 0.037 & -3.121 & $1.80 \mathrm{E}-03$ & $* *$ \\
\hline Down. Headway Change & 0.104 & 0.036 & 2.919 & $3.51 \mathrm{E}-03$ & $* *$ \\
\hline Disturbance & 2.114 & 0.764 & 2.767 & $5.66 \mathrm{E}-03$ & $* *$ \\
\hline Origin SW 4 ${ }^{\text {th }}$ Avenue & 1.275 & 0.510 & 2.501 & $1.24 \mathrm{E}-02$ & $*$ \\
\hline Visual Obstruction & 1.153 & 0.480 & 2.407 & $1.61 \mathrm{E}-02$ & $*$ \\
\hline Peds in CIA & 0.476 & 0.241 & 1.976 & $4.82 \mathrm{E}-02$ & $*$ \\
\hline SUV-Pickup & -1.110 & 0.607 & -1.827 & $6.77 \mathrm{E}-02$ &. \\
\hline Lincoln Red Light & 0.917 & 0.530 & 1.729 & $8.37 \mathrm{E}-02$ &. \\
\hline
\end{tabular}

Codes significance: “.” when $\mathrm{p}<0.10$; “*” when $\mathrm{p}<0.05$; “***”when $\mathrm{p}<0.01$ 


\subsection{DANGEROUS EVENTS}

This section presents a description of the most dangerous no-yield events. In these events the speeds of the vehicles, 122 feet away from the crosswalk, were over $40 \mathrm{mph}$. Due to their potential crash severity, it is worth reviewing the circumstances of these events.

The first event involved a passenger car coming down from SW 4th Avenue; this vehicle did not stop at Lincoln. The traffic volume on the study segment was low; when the vehicle crossed Lincoln there were no other vehicles downstream in the same lane. The upstream vehicle speed nearby Lincoln was $26.4 \mathrm{mph}$ and the speed approaching the crosswalk was $40.4 \mathrm{mph}$ (59.3 feet/second); the vehicle speed increased by $14.0 \mathrm{mph}$. A vehicle in another lane that did not yield to the pedestrian may have blocked the no-yield driver vision while a pedestrian was crossing. When the no-yield motorist could later see the pedestrian, the vehicle was 30 feet behind the crosswalk and the pedestrian had to rush to avoid being hit by the vehicle. If the pedestrian had been distracted the vehicle would have required a deceleration rate of $28.2 \mathrm{ft} / \mathrm{s} 2$. This deceleration rate is significantly higher than the safe deceleration rate of $10 \mathrm{ft} / \mathrm{s} 2$ recommended by the Institute of Transportation Engineers. The deceleration rate $a$ was calculated using this formula:

$S S D=v t+\frac{v^{2}}{2(a+G)}$

where:

$S S D=$ safe stopping distance, in this case $122 \mathrm{ft}$

$v=$ vehicle speed $122 \mathrm{ft}$ away from the crosswalk

$t=$ perception reaction time (1.0 second in urban areas)

$a=$ deceleration rate

$G=$ grade in percent (zero in this case)

The second event involved a passenger car that originated from I-405 and did not stop at Lincoln (the upstream intersection). The traffic volume on the study segment was low; when the no-yield vehicle crossed Lincoln, there were no other vehicles downstream in the same lane. The vehicle speed at the upstream intersection was $38.4 \mathrm{mph}$ and the speed approaching the crosswalk was $43.6 \mathrm{mph}$ (64.0 feet/second) (i.e., the vehicle speed increased by $5.2 \mathrm{mph}$ ). When the no-yield vehicle passed the decision zone, the pedestrian increased their walking speed significantly to avoid crashing with the vehicle. The vehicle passed the crosswalk behind the pedestrian. To get the vehicle to yield, a deceleration rate of $35.5 \mathrm{ft} / \mathrm{s} 2$ would have been required.

Several similarities can be observed among the most dangerous events: a) The vehicle did not encounter a red phase at the upstream intersection (SW Lincoln); b) The traffic volumes were relatively low; c) The vehicles accelerated (increased their speed significantly) between SW 
Lincoln and the decision zone; and d) The normal trajectory and speed of the pedestrians were severely disturbed.

In general, the characteristics of the most dangerous events support the results of the binary and ordered logistics models presented in the previous sections. Speed change was the most significant variable in the models and this variable is also prominent in the most dangerous events. Not stopping at a red light upstream and headway increases (typical with low traffic volumes) also support the results of the models. 


\subsection{CONCLUSIONS}

This research examines traffic and trajectory factors that explain whether a driver complies with the Oregon pedestrian laws. Data from detailed video records (several cameras at different heights) were utilized to analyze driver and vehicle trajectories up to 200 meters (650 feet) upstream of a crosswalk with a high record of pedestrian law violations. The modeling results indicate that speed and headway changes, as well as driving trajectory before reaching the crosswalk, are the most significant variables to predict crosswalk law compliance and stopping distance.

Novel results indicate that vehicle origin and stopping at upstream traffic lights affect compliance rates. Drivers who are coming from a freeway or do not stop at an upstream traffic light are more likely to be less compliant and stop closer to the crosswalk. In addition, changes in vehicle speed and headways are the most significant variables to predict pedestrian crosswalk law compliance and stopping behavior. This is the first research effort to analyze crosswalk stopping distance; it is notable that the variables that explain crosswalk compliance rates are also useful to explain stopping distance. Results also indicate that drivers are more likely to comply if the pedestrian stopped while crossing or had to speed up in response to approaching vehicles. Drivers of SUV/pickups tend to comply less than smaller passenger vehicles.

Pedestrians, even if they are acting lawfully as assumed in this research, are highly vulnerable while crossing a crosswalk with approaching oncoming traffic. At locations with high noncompliance rates, efforts must be made to increase pedestrian safety and stopping distance. It has been argued that the psychological comfort of pedestrians should be given more consideration because of the greater vulnerability at crosswalks (Hubbard et al., 2007). Enforcement and education campaigns, such as the campaigns executed by PBOT, can be useful to lower noncompliance rates and increase stopping distances. In addition, in some cases engineering measures may also be necessary.

This research effort has several limitations. It has focused only on pedestrians who fully comply with the law (i.e., not aggressive); future research efforts may consider how drivers' trajectory and behavior are affected by the level of pedestrian aggressiveness. Future research efforts should consider the comparison of crosswalks with high and low non-compliance rates and the analysis of more crosswalks in different environments. It is increasingly important to study the impact of distracted drivers and pedestrians on compliance rates. Future research efforts can also study interaction effects among crosswalks, for example how compliance at one crosswalk may affect compliance at downstream crosswalks.

The focus of this research is not on the effectiveness of a particular treatment or specific design recommendations. However, based on the model results it is highly likely that measures that can be taken to reduce vehicle speeds are very likely to improve compliance rates. Additional signage, especially for drivers coming from Interstate 405, may also result in higher compliance rates. Dynamic speed signs displaying approaching vehicle speeds may be useful to inform drivers as well as pedestrians. However, some research has shown that the positive impact of dynamic speed displays may wear off over time (Ardeshiri \& Jeihani, 2014). Forcing vehicles to stop at the upstream intersection (e.g., flashing red light) can provide a valuable visual and normative cue about appropriate driving speeds and solve the problem of speed adaptation, especially for drivers coming from I-405. Treatments like rectangular rapid flashing beacons have shown to increase yield rates substantially (Shrubutt et al., 2009). Changing the type of crosswalk (e.g., a raised 
crosswalk) may increase visibility and awareness (Zeeger et al., 2001). A more radical approach would involve changes in the cross-section of the street (e.g., street narrowing or even a road diet from three to two lanes); appropriate signage plus a road diet after crossing Lincoln Street (one block upstream from the crosswalks) would signal drivers that they are entering an urban area with heavy pedestrian traffic.

The results of this research suggest that treatments or driver notifications (Habibovic \& Davidsson, 2012) that discourage accelerating towards the crosswalk would be most useful to increase compliance. Previous studies have shown the potential positive payback of reducing traffic speeds to posted speed limits (Carsten \& Tate, 2005). Assuming non-aggressive pedestrian behavior, it can be speculated that connected vehicles with intelligent speed adaptation (i.e., reduction of speeds when entering more urban or pedestrian areas), and/or automated detection of pedestrians may greatly increase pedestrian safety and comfort levels. 


\subsection{APPENDIX}

Table 6. Descriptive Statistics - Significant Continuous/Integer Variables

\begin{tabular}{|l|r|r|r|r|r|r|}
\hline \multicolumn{1}{|c|}{ Variable } & \multicolumn{1}{c|}{ Min. } & 15th P. & \multicolumn{1}{c|}{ Avg. } & Med. & 85th P. & Max. \\
\hline Speed1 (mph) & 10.60 & 15.80 & 22.47 & 22.00 & 29.13 & 38.40 \\
\hline Speed2 (mph) & 2.20 & 13.60 & 21.69 & 21.80 & 28.30 & 43.60 \\
\hline Speed Change (mph) & -18.10 & -8.55 & -0.78 & -0.40 & 5.95 & 21.90 \\
\hline Dow. Headway1 (sec.) & 0.71 & 3.12 & 11.88 & 12.36 & 20.00 & 25.09 \\
\hline Dow. Headway2 (sec.) & 1.10 & 2.47 & 12.70 & 15.78 & 20.00 & 20.00 \\
\hline Dow. Headway Change (sec.) & -16.80 & -6.98 & -0.83 & 0.00 & 2.34 & 18.02 \\
\hline Peds in CIA & 0 & 0 & 0.97 & 1 & 2 & 5 \\
\hline
\end{tabular}

Table 7. Descriptive Statistics - Significant (bold) and Related Binary Variables

\begin{tabular}{|l|r|}
\hline \multicolumn{1}{|c|}{ Variable } & \multicolumn{1}{c|}{ Avg. } \\
\hline Disturbance & 0.07 \\
\hline Origin SW 4 & 0.46 \\
\hline Origin I-405 & 0.30 \\
\hline Origin other (Lincoln) & 0.24 \\
\hline Lincoln Red Light & 0.34 \\
\hline Adjacent Stopped & 0.30 \\
\hline SUV-Pickup & 0.22 \\
\hline Cars & 0.70 \\
\hline Other vehicle & 0.08 \\
\hline
\end{tabular}


Table 8. Correlations - Significant Variables

\begin{tabular}{|l|r|r|r|r|r|r|r|}
\hline \multicolumn{1}{|c|}{ Variable } & $\begin{array}{c}\text { Speed } \\
\text { Change } \\
\text { (mph) }\end{array}$ & $\begin{array}{c}\text { Dow. } \\
\text { Headway } \\
\text { Change } \\
\text { (sec.) }\end{array}$ & $\begin{array}{c}\text { Peds in } \\
\text { CIA }\end{array}$ & $\begin{array}{c}\text { Origin } \\
\text { SW } \\
\text { Ave. }\end{array}$ & $\begin{array}{c}\text { SUV- } \\
\text { Pickup }\end{array}$ & $\begin{array}{c}\text { Lincoln } \\
\text { red } \\
\text { light }\end{array}$ & $\begin{array}{c}\text { Adjacent } \\
\text { stopped }\end{array}$ \\
\hline Speed Change (mph) & 1 & 0.00 & -0.24 & 0.03 & 0.15 & 0.07 & -0.02 \\
\hline Dow. Headway Change (sec.) & 0.00 & 1 & -0.04 & -0.12 & -0.14 & -0.26 & 0.17 \\
\hline Peds in CIA & -0.24 & -0.04 & 1 & -0.06 & 0.14 & -0.09 & 0.30 \\
\hline Origin SW 4 ${ }^{\text {th }}$ Avenue & 0.03 & -0.12 & -0.06 & 1 & 0.02 & 0.17 & -0.15 \\
\hline SUV-Pickup & 0.15 & -0.14 & 0.14 & 0.02 & 1 & -0.03 & -0.09 \\
\hline Lincoln Red Light & 0.07 & -0.26 & -0.09 & 0.17 & -0.03 & 1 & -0.05 \\
\hline Adjacent Stopped & -0.02 & 0.17 & 0.30 & -0.15 & -0.09 & -0.05 & 1 \\
\hline
\end{tabular}




\subsection{REFERENCES}

Ardeshiri, A., \& Jeihani, M. (2014). A speed limit compliance model for dynamic speed display sign. Journal of safety research, 51, 33-40.

Bennett, M. K., Manal, H., \& Van Houten, R. (2014). A comparison of gateway in-street sign configuration to other driver prompts to increase yielding to pedestrians at crosswalks. Journal of applied behavior analysis, 47(1), 3-15

BikePortland (2015), Bike Portland, Entering 10th year, PBOT ‘crosswalk enforcement actions' still going strong, http://bikeportland.org/2015/01/28/entering-10th-year-pbot-crosswalkenforcement-actions-still-going-strong-131516, accessed September 11, 2015.

Britt, J., A. Bergman and J. Moffatt. "Law Enforcement, Pedestrian Safety, and Driver Compliance with Crosswalk Laws: Evaluation of a Four-year Campaign in Seattle,” Transportation Research Record 1485: Transportation Research Board, National Research Council, Washington, DC, 1995.

Campbell, B. , Zegeer, C. , Huang, H. , \& Cynecki, M. (2004). A review of pedestrian safety research in the United States and abroad, Publication No RD-03-042, FHWA.

Carsten, O. M., \& Tate, F. N. (2005). Intelligent speed adaptation: accident savings and cost-benefit analysis. Accident Analysis \& Prevention, 37(3), 407-416

Fisher, D., \& Garay-Vega, L. (2012). Advance yield markings and drivers’ performance in response to multiple-threat scenarios at mid-block crosswalks. Accident Analysis \& Prevention, 44, pp. 35-41.

Gårder, P. E. The impact of speed and other variables on pedestrian safety in Maine. Accident Analysis and Prevention, Vol. 36, 2004, pp. 533-542.

Hubbard, S., Awwad, R., \& Bullock, D. (2007). Assessing the impact of turning vehicles on pedestrian level of service at signalized intersections: a new perspective. Transportation Research Record: Journal of the Transportation Research Board, (2027), 27-36.

Habibovic, A., \& Davidsson, J. (2012). Causation mechanisms in car-to-vulnerable road user crashes: Implications for active safety systems.Accident Analysis \& Prevention, 49, 493-500.

ITE (1999), Institute of Transportation Engineers, Traffic Engineering Handbook, $5^{\text {th }}$ Ed., Washington, DC.

Katz, A., D. Zaidel, and A. Elgrishi. An Experimental Study of Driver and Pedestrian Interaction During the Crossing Conflict. Human Factors: The Journal of the Human Factors and Ergonomics Society, Vol. 17, 1975, pp. 514-527.

Kim, K., Brunner, I. M., \& Yamashita, E. (2008). Modeling violation of Hawaii's crosswalk law. Accident Analysis \& Prevention, 40(3), 894-904 
Kweon, Y. J., Hartman, S. E., \& Lynn, C. W. (2009). Stop versus yield on pedestrian-involved fatal crashes in the United States. Accident Analysis \& Prevention, 41(5), 1034-1039.

Lee, C., \& Abdel-Aty, M. (2005). Comprehensive analysis of vehicle-pedestrian crashes at intersections in Florida. Accident Analysis \& Prevention, 37(4), 775-786.

Mead, J., Zegeer, C., \& Bushell, M. (2014). Evaluation of Pedestrian-Related Roadway Measures: A Summary of Available Research. P a BI Center. Chapel Hill, NC, UNC Highway safety Research Center, 115.

NCHRP (1997), National Cooperative Highway Research Program 400, Determination of stopping sight distances. Transportation Research Board, Washington D.C., 2007.

NCHRPS (2011), National Cooperative Highway Research Program Synthesis 412, Speed Reduction Techniques for Rural High-to-Low Speed Transitions. Transportation Research Board, Washington D.C., 2011.

NHTSA (2015), National Highway Traffic Safety Administration. Traffic Safety Facts. http://wwwnrd.nhtsa.dot.gov/Pubs/812124.pdf, Accessed May 1, 2016.

NCLS (2015), Pedestrian Crossing: 50 State Summary, National Conference of State Legislatures, published April 20, 2015, Accessed March 1, 2016, http://www.ncsl.org/research/transportation/pedestrian-crossing-50-state-summary.aspx

ODOT (2014), Oregon Department of Transportation, Speed Zone Manual, January 2014, http://www.oregon.gov/odot/hwy/traffic-roadway/docs/pdf/speed_zone_manual.pdf , accessed June 10, 2014.

ODOT (2015), Oregon Department of Transportation, What you need to know about OREGON CROSSWALK LAWS http://www.oregon.gov/ODOT/TS/docs/pedestrian/Oregon\%20Crosswalk\%20Laws_re v_3-2015.pdf, accessed September 11, 2015.

ORS (2011), Oregon Revised Statutes, Vol. 17, 811.028 , Duties To Pedestrians And Bicycles, http://www.oregonlaws.org/ors/811.028, accessed September 11, 2015.

Papadimitriou, E., Yannis, G., \& Golias, J. (2009). A critical assessment of pedestrian behaviour models. Transportation research part F: traffic psychology and behaviour, 12(3), 242-255.

PBOT (2014), Portland Maps Online, http://www.portlandmaps.com/. Accessed July 10, 2014.

PBOT (2015), Portland Bureau of Transportation, Pedestrian Crosswalk Enforcement Actions, http://www.portlandoregon.gov/transportation/article/134382, accessed September 11, 2015.

Phillips, R. O., Ulleberg, P., \& Vaa, T. (2011). Meta-analysis of the effect of road safety campaigns on accidents. Accident Analysis \& Prevention, 43(3), 1204-1218.

Schroeder, B. J., and N. M. Rouphail. Event-Based Modeling of Driver Yielding Behavior at Unsignalized Crosswalks. Journal of Transportation Engineering, Vol. 137, 2011, pp. 455-465.

Shurbutt, J., Van Houten, R., Turner, S., \& Huitema, B. (2009). Analysis of effects of LED rectangular rapid-flash beacons on yielding to pedestrians in multilane crosswalks. Transportation Research Record 2140, 85-95.

Turner, S., Fitzpatrick, K., Brewer, M., \& Park, E. (2006). Motorist yielding to pedestrians at unsignalized intersections: Findings from a national study on improving pedestrian safety. Transportation Research Record 1982, 1-12. 
Van Houten, R. (1988) The Effects of Advance Stop Lines and Sign Prompts on Pedestrian Safety in a Crosswalk on a Multilane Highway. Journal of Applied Behavior Analysis, Vol. 21, 1988, pp. 245-251.

Zegeer, C., Stewart, J., Huang, H., \& Lagerwey, P. (2001). Safety effects of marked versus unmarked crosswalks at uncontrolled locations: analysis of pedestrian crashes in 30 cities. Transportation Research Record 1773, 56-68. 
Transportation Research and Education Center

Portland State University

1900 S.W. Fourth Ave., Suite 175

Portland, OR 97201 